\title{
GAMBARAN PENGETAHUAN TENTANG TEKNIK MENYIKAT GIGI DAN KARANG GIGI PADA SISWA KELAS 1 SMP BENIH PAPUA DI TIMIKAPROVINSI PAPUA BARAT
}

\author{
Tabita Tonglo ${ }^{1}$ Jeana Lydia Maramis ${ }^{2}$ \\ 2) Dinas Kesehatan Kab,Timika Jl. Budi Utomo, Kwamki Kab,Mimika.Prop.Papua \\ 2)Jurusan Keperawatan Gigi Poltekkes Kemenkes ManadoJl.RW Mongisidi Malalayang II Manado
} Email : $\underline{\text { tonglo30@gmail.com }}$

\begin{abstract}
ABSTRAK
Latar Belakang : Karang gigi adalah masa padat yang berasal dari plak dari debris yang mengalami kalsifikasi yang terbentuk dan melekat erat pada permukaan gigi yang warnanya berwarna kekuning-kuningan sampai coklat kehijauan. Jika karang gigi ini tidak langsung dibersihkan maka akan mengakibatkan gigi goyang, gingivitis dan periodontitis serta bau mulut. Karang gigi dapat dicegah dengan memelihara kesehatan gigi dan mulut. Cara menyikat gigi adalah cara yang umum dianjurkan untuk membersihkan deposit lunak pada permukaan gigi dan gusi dan merupakan tindakan preventif dalam menuju keberhasilan dan kesehatan rongga mulut yang optimal (Putri dkk, 2009). Tujuan : Penelitian ini bertujuan untuk mengetahui gambaran pengetahuan tentang teknik menyikat gigi dan karang gigi pada siswa kelas I SMP Benih Papua di Timika Propinsi Papua Barat. Metode : Jenis penelitian ini yaitu deskriptif untuk mengambarkan pengetahuan teknik menyikat gigi dan karang gigi. Sampel dalam penelitian ini yaitu 36 orang siswa di SMP Benih Papua Timika. Data yang diperoleh kemudian ditabulasi dan dianalisis menggunakan distribusi frekuensi. Hasil : Hasil yang didapat dalam penelitian ini yaitu pengetahuan yang kurang baik mengenai teknik menyikat gigi mendapat indeks karang gigi dengan kriteria buruk paling banyak (89\%), Kesimpulan : hal ini dapat disimpulkan bahwa jika responden memiliki pengetahuan tentang teknik menyikat gigi kurang baik maka kriteria karang gigi akan buruk juga.
\end{abstract}

\section{Kata kunci : Pengetahuan menyikat gigi, karang gigi}

\section{ABSTRACT}

Introduction : Calculus is a solid mass that comes from plaque from calcified debris that forms and sticks tightly to the surface of the teeth, which are yellowish to greenish brown in color. If the calculus is not cleaned immediately it will cause loose teeth, gingivitis and periodontitis as well as bad breath. Dental calculus can be prevented by maintaining healthy teeth and mouth. How to brush your teeth is a commonly recommended way to clean soft deposits on the surface of the teeth and gums and is a preventive measure towards the success and optimal health of the oral cavity (Putri et al., 2009). Objective : This study aims to determine the knowledge of the technique of brushing teeth and tartar in grade I SMP Benih Papua in Timika, West Papua Province. Methods : This type of research is descriptive to describe the knowledge of brushing techniques and tartar. The sample in this study were 36 students at SMP Benih Papua Timika. The data obtained were then tabulated and analyzed using a frequency distribution. Result : The results obtained in this study were poor knowledge about brushing techniques, getting the tartar index with the most bad criteria (89\%). Conclusion : it can be conclude that poor of knowledge of brushing the teeth may cause a poor criteria of calculus. 
Key words: Knowledge, brush teeth, tartar

\section{PENDAHULUAN}

Kesehatan gigi dan mulut merupakan bagian dari kesehatan tubuh yang tidak dapat dipisahkan satu dengan yang lainnya sebab kesehatan gigi dan mulut akan mempengaruhi kesehatan tubuh secara keseluruhan. Untuk menjaga kesehatan gigi dan mulut dibutuhkan pengetahuan. Pengetahuan adalah hasil dari tahu dan ini terjadi setelah orang melakukan penginderaan terhadap objek tertentu. Penginderaan terjadi melalui panca indera manusia, yakni indera penglihatan, pendengaran, penciuman, rasa dan raba. Sebagaian besar pengetahuan manusia diperoleh melalui mata dan telinga. Pengetahuan bisa diperoleh secara alami maupun secara terencana yaitu melalui proses pendidikan $^{1}$

Seseorang dapat memelihara kesehatan gigi dan mulutnya dikarenakan telah mendapat pengetahuan tentang cara memelihara kesehatan gigi dan mulut. Untuk menjaga kesehatan gigi dan mulut dengan baik, maka harus mengetahui teknik menyikat gigi dengan baik dan benar. Cara menyikat gigi adalah cara yang umum dianjurkan untuk membersihkan deposit lunak pada permukaan gigi dan gusi dan merupakan tindakan preventif dalam menuju keberhasilan dan kesehatan rongga mulut yang optimal. ${ }^{2}$

Teknik menyikat gigi yang sering dianjurkan yaitu roll technic, karena teknik ini sederhana tetapi efisien dan dapat digunakan di seluruh bagian mulut. Cara menyikat gigi dengan rool technic yaitu : bulu-bulu sikat ditempatkan pada gusi sejauh mungkin dari permukaan oklusal dengan ujung bulu-bulu sikat mengarah ke apeks dan sisi bulu sikat digerakkan secara perlahan-lahan, melalui dari permukaan gigi sehingga bagian belakang dari kepala sikat bergerak dengan lengkungan. Pada waktu bulu sikat melalui mahkota klinis, kedudukannya hampir tegak lurus pada permukaan email. Gerakan ini diulang 812 kali setiap daerah dengan sistematis sehingga tidak ada yang terlewatkan.

Karang gigi merupakan suatu masa yang mengalami klasifikasi yang terbentuk dan melekat erat pada permukaan gigi. ${ }^{2}$. Karang gigi merupakan suatu faktor iritasi yang terus menerus terhadap gusi sehingga dapat menyebabkan peradangan pada gusi. Bila tidak dihilangkan maka akan berlanjut pada kerusakan jaringan penyanggah gigi dan lama kelamaan mengakibatkan gigi menjadi goyang serta lepas dengan sendirinya $^{3}$. Adapun jenis-jenis karang gigi yaitu :

a. Karang gigi supra gingival

Karang gigi supra gingival adalah karang gigi yang melekat pada permukaan gigi mulai dari gingival margin dan dapat dilihat. Karang gigi supra gingival ini berwarna putih kekuning-kuningan dan mudah dibersihkan dengan menggunakan scaler.

b. Karang gigi sub gingival

Karang gigi sub gingival adalah karang gigi yang berada dibawah batas gingival margin, biasanya pada daerah saku gusi dan tak dapat terlihat pada waktu pemeriksaan. Karang gigi ini berwarna coklat tua atau hijau kehitam-hitaman. $^{2}$

Karang gigi ini terbentuk dari plak yang termineralisasi. Bila plak dibiarkan lama sehingga bersifat basa, dan dengan adanya 
zat metabolisme, maka kalsium dari saliva akan mengendap pada lapisan plak sehingga tejadi pengapuran lapisan plak tersebut sehingga menjadi karang gigi.

Pemeriksaan karang gigi dilakukan untuk memudahkan penilaian. Pemeriksaan karang gigi pada gigi tertentu dan pada permukaan tertentu dari gigi tersebut yaitu :

a. Untuk rahang atas yang diperiksa :

1. Gigi molar kanan atas pada permukaan buccal

2. Gigi incisivus kanan atas pada permukaan labial

3. Gigi molar kiri atas pada permukaan buccal

b. Untuk rahang bawah yang diperiksa :

1. Gigi molar kiri bawah pada permukaan lingual

2. Gigi incisivus kiri bawah pada permukaan labial

3. Gigi molar kanan bawah pada permukaan lingual

Bila ada kasus salah satu dari gigi tersebut tidak ada (telah dicabut/tinggal sisa akar), penilaian dilakukan pada gigigigi pengganti yang sudah ditetapkan untuk mewakilinya, yaitu :

a. Bila gigi molar pertama rahang atas atau rahang bawah tidak ada penilaian dilakukan pada gigi molar kedua rahang atas atau bawah.

b. Bila gigi molar pertama dan kedua rahang atas atau rahang bawah tidak ada, penilaian dilakukan pada gigi molar ketiga rahang atas atau rahang bawah.

c. Bila molar pertama, molar kedua, dan ketiga rahang atas atau rahang bawah tidak ada, tidak dapat dilakukan penilaian.

d. Bila gigi incisivus pertama kanan rahang atas tidak ada, penilaian dilakukan pada incisivus pertama kiri rahang atas. e. Bila gigi incisivus pertama kanan dan kiri rahang atas tidak ada, tidak dapat dilakukan penilaian.

f. Bila gigi pertama kiri rahang bawah tidak ada, penilaian dilakukan pada gigi incisivus pertama kanan rahang bawah.

g. Bila gigi incisivus pertama kiri dan kanan rahang bawah tidak ada, tidak dapat dilakukan penilaian.

Penilaian karang gigi dapat dilihat pada Tabel 1 berikut ini :

Tabel 1. Kriteria Skor Karang Gigi

\begin{tabular}{cl}
\hline Skor & \multicolumn{1}{c}{ Kondisi } \\
\hline 0 & Tidak ada karang gigi \\
1 & Pada permukaan gigi terlihat
\end{tabular}
karang gigi supra gingival menutupi permukaan gigi kurang dari $1 / 3$ permukaan gigi.

2 Permukaan gigi terlihat karang supra gingival menutupi permukaan gigi lebih dari $2 / 3$.

Sekitar sebagian servikal gigi terdapat sedikit karang gigi sub gingival.

3 Pada permukaan gigi terdapat karang gigi supra gingival yang menutupi lebih dari $2 / 3$ atau seluruh permukaan gigi. Pada permukaan gigi ada karang gigi sub gingival yang menutupi permukaan gigi atau melingkar pada servikal gigi.

Cara perhitungan Calculus Index :

$\mathbf{C I}=$ Jumlah penilaian Kalkulus Jumlah gigi yang diperiksa

Skor karang gigi :

1. Baik apabila nilainya antara $0-0,6$

2. Sedang apabila nilainya antara $0,7-1,8$

3. Buruk apabila nilainya antara 1,9 $3,0 .^{2}$ 
Karang gigi (Calculus) dapat dicegah dengan cara :

a. Menyikat gigi dengan benar minimal 2 kali sehari secara benar.

b. Makan buah-buahan yang berserat dan berair.

c. Mengunyah makanan dengan menggunakan 2 sisi rahang, karena bagian rahang yang tidak dipakai untuk mengunyah sangat mudah untuk terbentuk karang gigi.

d. Memeriksakan kesehatan gigi 6 bulan sekali atau 2 kali dalam setahun ke rumah sakit, puskesmas atau poli gigi. ${ }^{4}$

Siswa Sekolah Menengah Pertama (SMP) dapat dikategorikan sebagai anak usia remaja awal. Pada umumnya usia Sekolah Menengah Pertama adalah masa remaja awal setelah mereka melalui masamasa pendidikan Sekolah Dasar. Masa remaja awal atau masa puber adalah masa peralihan dari kanak-kanak ke remaja Masa remaja adalah suatu masa perubahan.Pada masa remaja terjadi perubahan yang cepat baik secara fisik maupun psikologis.Ada beberapa perubahan yang terjadi selama masa remaja. Misalnya pada perempuan akan mengalami menstruasi yang menandakan bahwa organ produksinya sudah berfungsi. $^{5}$

\section{METODE}

Jenis penelitian yang digunakan yaitu deskriptif (Notoatmodjo, 2010). Metode ini menggambarkan atau mendeskriptifkan tentang teknik menyikat gigi dan karang gigi. Data yang dikumpulkan di lapangan secara nyata. ${ }^{6}$

Responden dalam penelitian ini yaitu 36 orang siswa SMP Benih Papua Timika Papua Barat. Analisa yang digunakan pada penelitian ini dengan cara menghitung persentasi atau dibuat distribusi frekuensi.

\section{HASIL}

1. Distribusi Responden Menurut Kelompok Umur

Tabel 2. Distribusi Responden Menurut Kelompok Umur

\begin{tabular}{ccc}
\hline $\begin{array}{c}\text { Umur } \\
\text { (Tahun) }\end{array}$ & Jumlah & $\begin{array}{c}\text { Persentase } \\
(\boldsymbol{\%})\end{array}$ \\
\hline 12 & 2 & 5.5 \\
13 & 28 & 77.8 \\
14 & 6 & 16.7 \\
\hline Total & $\mathbf{3 6}$ & $\mathbf{1 0 0}$ \\
\hline
\end{tabular}

Dari Tabel 2 di atas menunjukkan bahwa umur responden sebagai besar berada pada kelompok umur 13 tahun yaitu sebanyak 28 responden $(77,8 \%)$, umur 12 tahun sebanyak 2 responden $(5,5 \%)$, dan paling sedikit umur 14 tahun sebanyak 6 responden $(16,7 \%)$.

2. Distribusi Responden Menurut Jenis kelamin

Tabel 3. Distribusi Responden Menurut Jenis Kelamin

\begin{tabular}{ccc}
\hline $\begin{array}{c}\text { Jenis } \\
\text { Kelamin }\end{array}$ & Jumlah & $\begin{array}{c}\text { Persentase } \\
(\boldsymbol{\%})\end{array}$ \\
\hline Laki-laki & 19 & 52.8 \\
Perempuan & 17 & 47.2 \\
\hline Total & $\mathbf{3 6}$ & $\mathbf{1 0 0}$ \\
\hline
\end{tabular}

Dilihat dari Tabel 3 di atas menunjukkan bahwa responden laki-laki lebih banyak (52.8\%) dibandingkan dengan perempuan $(47,2 \%)$. 
3. Distribusi Responden Menurut Pengetahuan dan Karang Gigi

Tabel 4. Distribusi Responden Menurut Pengetahuan Dan Karang Gigi

\begin{tabular}{|c|c|c|c|c|c|}
\hline \multirow{2}{*}{ Pengetahuan } & \multicolumn{3}{|c|}{ Karang gigi } & \multirow{2}{*}{ Total } & \multirow{2}{*}{$\%$} \\
\hline & Baik & Sedang & Buruk & & \\
\hline Baik & 1 & 3 & 0 & 4 & 11 \\
\hline Kurang Baik & 0 & 0 & 32 & 32 & 89 \\
\hline Total & 1 & 3 & 32 & 36 & 100 \\
\hline
\end{tabular}

Dilihat pada Tabel 4 di atas menunjukkan bahwa responden dengan pengetahuan baik dan kriteria karang gigi baik hanya 1 responden, sedangakn kriteria sedang ada 3 responden. Pada pengetahuan kurang baik dan kriteria karang gigi buruk sebanyak $32(89 \%)$ responden,

\section{PEMBAHASAN}

$\begin{array}{llll}\text { Menyikat gigi merupakan suatu } & \text { dilakukan untuk }\end{array}$ membersihkan gigi dari sisa makanan .Menyikat gigi sebaiknya dilakukan dengan baik dan benar.Cara menyikat gigi yang baik dan benar yaitu pada bagian yang menghadap pipi sebaiknya dengan cara naik turun atau dengan cara memutar, bagian yang menghadap bibir dengan cara naik turun, bagian gigi yang menghadap lidah dengan cara mengait dan bagian pengunyahan dengan cara maju mundur. ${ }^{2}$ Jika siang hari tidak sempat menyikat gigi, dapat diganti dengan makan buah-buahan yang berserat dan berair yang dapat mengurangi sisa makanan yang melekat pada gigi ${ }^{7}$

Kebersihan gigi dan mulut yang tidak diperhatikan dapat menyebabkan sisa-sisa makanan yang bertumpuk pada lapisan plak yang sudah mengalami remineralisasi sehingga berubah konsistensinya menjadi keras yang disebut dengan karang gigi. Karena permukaannya yang kasar, karang gigi sering menjadi tempat retensi sisa makanan hingga berpotensi sebagai penyebab terjadinya peradangan pada gusi. Karang gigi juga mengandung banyak sekali bakteri dari berbagai jenis, karena itu gigi yang ditempeli karang gigi, gusinya sering kali berdarah dan apabila dibiarkan terus menerus lama kelamaan karang gigi akan bertambah banyak dan terus menekan gusi ke arah apical melalui permukaan akar gigi sehingga saku gusi akan bertambah dalam dan dapat mengakibatkan kerusakan jaringan periodontal bahkan dapat menyebabkan gigi goyang dan lepas dengan sendirinya. Jadi, agar kesehatan gigi dan mulut tetap terjaga kita harus menjaga kebersihan gigi dan mulut agar terhindar dari karang gigi sehingga keadaan jaringan periodontal tetap sehat. ${ }^{8}$

Berdasarkan hasil penelitian yang dilakukan tentang maka didapat bahwa distribusi pengetahuan dan karang gigi responden, sebagian besar responden berada pada kategori pengetahuan kurang baik yaitu sebanyak 32 (89\%) responden dan hanya $4(11 \%)$ responden yang masuk dalam kategrori pengetahuan baik. Untuk skor karang gigi sebagian besar juga responden berada pada kategori buruk yaitu sebanyak 32 (89\%) responden, sedangkan yang berkategori sedang $3(8 \%)$ responden dan berkategori baik 1 (3\%) responden. Responden yang pengetahuannya kurang baik maka karang gigi berada pada kriteria buruk. Hal ini disebabkan karena responden kurang memahami tentang cara menyikat gigi yang baik dan benar, sehingga responden menyikat gigi hanya pada waktu mandi saja, baik mandi dipagi hari maupun mandi pada sore hari. Responden juga suka mengkonsumsi makanan yang manis dan 
mudah melekat, seperti coklat, permen dan lain sebagainya, sehingga kebersihan gigi tidak terjaga dan mengakibatkan karang gigi banyak terbentuk.

\section{KESIMPULAN}

Berdasarkan hasil penelitian yang dilakukan pada siswa kelas I SMP Benih Papua Timika di Papua Barat yang berjumlah 36 siswa, dapat disimpulkan bahwa responden yang memiliki pengetahuan tentang teknik menyikat gigi yang kurang baik maka mendapatkan karang gigi dengan kriteria buruk.

\section{SARAN}

Bagi siswa SMP Benih Papua Timika agar dapat :

1. Menyikat gigi sesuai dengan teknik yang dianjurkan yaitu pada bagian yang menghadap pipi sebaiknya dengan cara naik turun atau dengan cara memutar, bagian yang menghadap bibir dengan cara naik turun, bagian gigi yang menghadap lidah, cara mengait dan bagian pengunyahan dengan cara maju mundur.

2. Mengurangi makan makanan yang manis dan mudah melekat pada permukaan gigi.

3. Dapat mengunjungi poliklinik gigi di Rumah Sakit atau di Puskesmas untuk melakukan pembersihan karang gigi.

\section{DAFTAR PUSTAKA}

1. Notoatmodjo, 2007. Promosi Kesehatan Ilmu Dan Seni. Rineka Cipta, Jakarta.

2. Putri dkk, 2009. .Ilmu Pencegahan Jaringan Keras dan Jaringan Pendukung Gigi. EGC, Jakarta

3. Artawa, 2010. Perbedaan kondisi karang gigi pada masyarakat yang mengkonsumsi air sumur dengan bukan air sumur. http://www.unmas.ac.id/PDF/Vol 8 No $\underline{1}$

4. Anonim. 2012. Karang gigi bikin vertigo dan bau mulut. http://depoklik.com/2012/01/25/karanggigi-bikin-vertigo-dan-bau mulut.html.

5. Nirwana. 2011. Psikologi Kesehatan Wanita (remaja, menstruasi, menikah, hamil, nifas, menyusui). Nuha Medika, Yogyakarta.

6. Notoatmodjo, 2010. Promosi Kesehatan dan Ilmu Perilaku. Rineka Cipta, Jakarta.

7. Mediacastore, 2008. Bau mulut, kesehatan gigi dan mulut, puasa, gingivitis.

http://medicastore.com/med/artikel.php? $\mathrm{id}=246 \&$ keyword

8. Rahmadhan. 2010. Serba Serbi Kesehatan Gigi dan Mulut. Bukune, Jakarta. 